\title{
Flow Visualization and Modeling for Education and Research in Sedimentary Processes: An Accessible and Inexpensive Alternative
}

\author{
Kannipa Motanated \\ Department of Geological Sciences, Faculty of Science, Chiang Mai University, Chiang Mai, Thailand \\ Email: kannipa.motanated@cmu.ac.th
}

How to cite this paper: Motanated, K. (2017) Flow Visualization and Modeling for Education and Research in Sedimentary Processes: An Accessible and Inexpensive Alternative. Journal of Geoscience and Environment Protection, 5, 1-8.

https://doi.org/10.4236/gep.2017.59001

Received: July 6, 2017

Accepted: August 20, 2017

Published: August 23, 2017

Copyright $\odot 2017$ by author and Scientific Research Publishing Inc. This work is licensed under the Creative Commons Attribution International License (CC BY 4.0).

http://creativecommons.org/licenses/by/4.0/

\begin{abstract}
Sedimentary processes have direct effects on the geometry, distribution, and geophysical and geochemical properties of sedimentary rocks. Being able to qualitatively and quantitatively visualize the movement vector of sediments in fluid media is essential for understanding the complicated earth surface processes. Nonintrusive measuring and observing the interaction between the movement of fluid media and particles by a laser sheet flow visualization technique requires a light source that is thin and monochromatic. Yet, an ideal laser sheet generator is rather expensive and inaccessible, especially for schools and universities residing in low-income countries. This project is proposing a less-expensive option for a laser sheet source for nonintrusive flow visualization and modeling. Here, cylindrical lens is used to convert from point laser into sheet laser. Multiple combinations of laser diodes of various wavelength (nanometer) and power (milliwatt) and cylindrical lenses of various dimensions are analyzed. The pair that is able to produce the thinnest and brightest light sheet is not only effective but also affordable. The combination of manufactured laser module of $532 \mathrm{~nm} 50 \mathrm{~mW}$ and a single rod lens is able to generate a light sheet that is less than $4 \mathrm{~mm}$ thick. When choosing a laser module, this research recommends one at a wavelength of $532 \mathrm{~nm}$ with any electric power (high wattage results in high lumens).
\end{abstract}

\section{Keywords}

Particle Image Velocimetry, Laser Sheet

\section{Introduction}

Particle velocity measurement and flow pattern visualization of particles in fluid media have been subjects of interest in many research fields including, but not 
limited to, earth sedimentary processes, fuel injection and spray, automation, and hemodynamics [1] [2] [3] due to their endless versatility. The techniques for quantitative particle velocity identification have been engineered, both empirically and theoretically, to increase their accuracy and accommodate the goals of each research. Available techniques used for measuring flow velocity are laser Doppler velocimetry, hot-wire anemometry, and particle image velocimetry (PIV); the former two techniques can only measure the velocity at a point while the latter technique is nonintrusive and can produce 2- and 3-dimensional velocity vector fields [4] [5] [6]. Thus, PIV technique has been treated as the dominant method for particle image velocimetry [6].

This research is particularly interested in quantitative geological aspect, such as earth surface process and sedimentary process modeling, of particle flow visualization via PIV technique because it is nonintrusive and able to produce multidimensional velocity vector fields. The experiment setup of this technique requires a light source that is thin and monochromatic in order to illuminate sediments or tracers in the flow [5]. However, an ideal laser sheet generator is rather expensive, especially for schools and universities residing in low-income countries, and requires multiple adjustable telescopic lenses to setup [7]. This project is proposing a less-expensive and simple to setup option for a laser sheet source and flow visualization experiment configuration for quantitative observation and analysis of the interaction between fluid media and sediments. Advantages and disadvantages of the proposed laser sheet source are also discussed here.

\section{Material and Method}

This research has chosen manufactured laser modules because they are widely accessible and relatively inexpensive, less than 35 USD for each laser module depending on its wavelength and electric power. This research is comparing the dimension of the light sheets produced from four different (wavelength and electric power) laser modules-650 nm $100 \mathrm{~mW}, 650 \mathrm{~nm} 30 \mathrm{~mW}, 532 \mathrm{~nm} 50$ $\mathrm{mW}$, and $405 \mathrm{~nm} 100 \mathrm{~mW}$ (Figure 1). The considered dimensions of light sheet are sheet thickness, length, and focusing distance [7] because they determine the

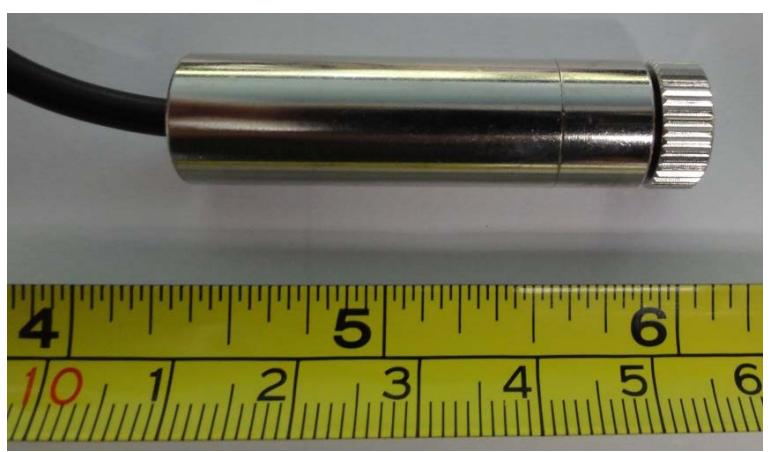

Figure 1. A $650 \mathrm{~nm} 30 \mathrm{~mW}$ laser dot module with twistable cap for replaceable lens. 
size of a plane of the flow as well as the size of the flow tank. An ideal light sheet has to be thin in order to limit the width of view of the illuminated region. Doing so can lower the amount of overlapping particles being recorded. An ideal laser module has to be able to produce a light sheet that has a consistent thickness so that the recorded field of view's dimensions are constant throughout the whole flow field. This generates high signal to noise ratio and low amount of parasite scattered light [7] [8]. Doing this enables a trustworthy qualitative and quantitative observation of spatial flow structures [5].

Typical manufactured laser modules generate laser dot; thus, beam shaping optics are required to convert laser dot into laser sheet [5] [6] [8]. Cylindrical optical components have been used to produce static laser sheets/planes and are regularly used in both aerodynamics and hydrodynamics experiments [7]. This research is using manufactured cylindrical glass lens to convert laser dot into laser sheet (Figure 2). Light sheet thickness and length are measured at 30, 50, and $70 \mathrm{~cm}$ from light source in order to determine the uniformity of light sheet's dimension. The three distances are chosen based on the width of the experimental flow tank used in [9]. Width, length, and changes of laser width at various distance of measurement are shown in Table 1 and Table 2.

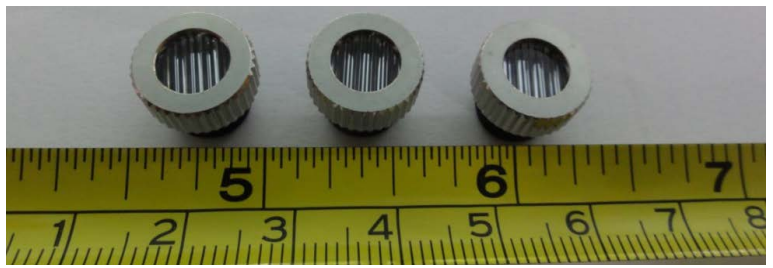

Figure 2. Laser dot to laser line optical converters, 60, 90, and 12 degrees from left to right. Multiple rod lenses are aligned so they are reminiscent of Fresnel lens. Referred as pseudo-Fresnel lens in this research.

Table 1. Laser sheet width and length at distances from laser source to background of 30 , 50 , and $70 \mathrm{~cm}$.

\begin{tabular}{|c|c|c|c|c|c|c|c|}
\hline \multirow{3}{*}{$\begin{array}{l}\text { Testing } \\
\text { group }\end{array}$} & \multirow{3}{*}{ Laser module } & \multicolumn{6}{|c|}{ Distance $(\mathrm{cm})$ from light source to background } \\
\hline & & \multicolumn{3}{|c|}{30} & \multicolumn{2}{|l|}{50} & 70 \\
\hline & & $\begin{array}{l}\text { width } \\
(\mathrm{mm})\end{array}$ & $\begin{array}{l}\text { length } \\
(\mathrm{cm})\end{array}$ & $\begin{array}{l}\text { width } \\
(\mathrm{mm})\end{array}$ & $\begin{array}{l}\text { length } \\
(\mathrm{cm})\end{array}$ & $\begin{array}{l}\text { width } \\
(\mathrm{mm})\end{array}$ & $\begin{array}{l}\text { length } \\
(\mathrm{cm})\end{array}$ \\
\hline \multirow[b]{2}{*}{1} & $650 \mathrm{~nm} 100 \mathrm{~mW}$ & 4.8 & 55.0 & 3.9 & 92.0 & 3.2 & 124.5 \\
\hline & $\begin{array}{c}650 \mathrm{~nm} 30 \mathrm{~mW} \\
\left(90^{\circ} \text { lens }\right)\end{array}$ & 14.2 & 57.0 & 19.5 & 94.5 & 24.4 & 134.0 \\
\hline \multirow{3}{*}{2} & $650 \mathrm{~nm} 30 \mathrm{~mW} 60^{\circ}$ lens & 17.6 & 41.5 & 24.9 & 66.5 & 31.1 & 93.0 \\
\hline & $650 \mathrm{~nm} 30 \mathrm{~mW} 90^{\circ}$ lens & 14.2 & 57.0 & 19.5 & 94.5 & 24.4 & 134.0 \\
\hline & $\begin{array}{c}650 \mathrm{~nm} 30 \mathrm{~mW} \\
120^{\circ} \text { lens }\end{array}$ & 13.6 & 75.0 & 19.6 & 119.5 & 27.2 & 164.0 \\
\hline 3 & $405 \mathrm{~nm} 100 \mathrm{~mW}$ & $3.6^{\mathrm{a}}$ & 88.2 & 3.5 & 141.5 & 3.4 & 201.6 \\
\hline 4 & $532 \mathrm{~nm} 50 \mathrm{~mW}$ & 3.7 & 150.0 & $3.1^{\mathrm{a}}$ & 330.0 & $2.4^{\mathrm{a}}$ & 310.0 \\
\hline
\end{tabular}

${ }^{\mathrm{a} T h e}$ thinnest laser sheet. 


\section{Results}

The laser modules are divided into four testing groups (Table 1). The first testing group compares laser module at a wavelength of $650 \mathrm{~nm}$ and electric power of $30 \mathrm{~mW}$ with that of the same wavelength at $100 \mathrm{~mW}$. This testing group allows the observation of laser sheet quality with respect to electric energy. The second group tests the laser-dot-to-sheet converting ability of psudo-Fresnel lenses (Table 1). The third group compares the ability of two laser modules of equal electric energy but different wavelength, $405 \mathrm{~nm} 100 \mathrm{~mW}$ and $650 \mathrm{~nm} 100$ $\mathrm{mW}$ of the first group. This testing group allows the observation of laser sheet quality with respect to wavelength. The fourth testing group consists of one laser module. This testing group observes the laser sheet quality produced from 532 $\mathrm{nm}$ laser module which generates green light which is within the wavelength spectrum that human eye and camera lens have high percentage of sensitivity [10]. This last testing group only consists of one laser module because ones with different wattage are unavailable.

The results of this research are displayed in Table 1 and Table 2. Light sheet produced from single rod lens is narrow and long but tapered on both ends (Figure 3) while that produced from pseudo-Fresnel lens is nonhomogeneous and fanning out on both ends (Figure 4). The laser sheet intensity profiles emitted from both single rod lens and pseudo-Fresnel lens are not a true light plane; areas of low intensity are present along the boundary of the laser sheet (Figure 3 and Figure 4). Laser modules of $405 \mathrm{~nm} 100 \mathrm{~mW}$ and $532 \mathrm{~nm} 50 \mathrm{~mW}$ produced by single rod lens are able to generate the thinnest laser sheet (Table 1) as well as

Table 2. The differences of laser sheet width at distances from laser source to background of 30,50 , and $70 \mathrm{~cm}$.

\begin{tabular}{|c|c|c|c|c|c|c|}
\hline $\begin{array}{c}\text { Testing } \\
\text { group }\end{array}$ & Laser module & $\begin{array}{l}\text { aser widtl } \\
\text { at } 30 \mathrm{~cm} \\
\left(\mathrm{~W}_{30}\right)\end{array}$ & $\begin{array}{l}\text { Laser width } \\
\text { at } 50 \mathrm{~cm} \\
\left(\mathrm{~W}_{50}\right)\end{array}$ & $\begin{array}{l}\text { Laser width } \\
\text { at } 70 \mathrm{~cm} \\
\quad\left(\mathrm{~W}_{70}\right)\end{array}$ & $\begin{array}{c}\mathrm{W}_{30}-\mathrm{W}_{50} \\
(\mathrm{~mm})\end{array}$ & $\begin{array}{c}\mathrm{W}_{50}-\mathrm{W}_{70} \\
(\mathrm{~mm})\end{array}$ \\
\hline \multirow{2}{*}{1} & $650 \mathrm{~nm} 100 \mathrm{~mW}$ & 4.8 & 3.9 & 3.2 & 0.9 & 0.67 \\
\hline & $650 \mathrm{~nm} 30 \mathrm{~mW}\left(90^{\circ}\right.$ lens $)$ & 14.2 & 19.5 & 24.4 & -5.3 & -4.9 \\
\hline \multirow{3}{*}{2} & $650 \mathrm{~nm} 30 \mathrm{~mW} 60^{\circ}$ lens & 17.6 & 24.9 & 31.1 & -7.3 & -6.2 \\
\hline & 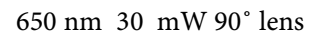 & 14.2 & 19.5 & 24.4 & -5.3 & -4.9 \\
\hline & $650 \mathrm{~nm} 30 \mathrm{~mW} 120^{\circ}$ lens & 13.6 & 19.6 & 27.2 & -6.0 & -7.6 \\
\hline 3 & $405 \mathrm{~nm} 100 \mathrm{~mW}$ & 3.6 & 3.5 & 3.4 & $0.1^{\mathrm{b}}$ & $0.1^{\mathrm{b}}$ \\
\hline 4 & $532 \mathrm{~nm} 50 \mathrm{~mW}$ & 3.7 & 3.1 & 2.4 & $0.6^{\mathrm{b}}$ & $0.7^{\mathrm{b}}$ \\
\hline
\end{tabular}

${ }^{\mathrm{b}}$ The most consistent laser sheet width at multiple distances.

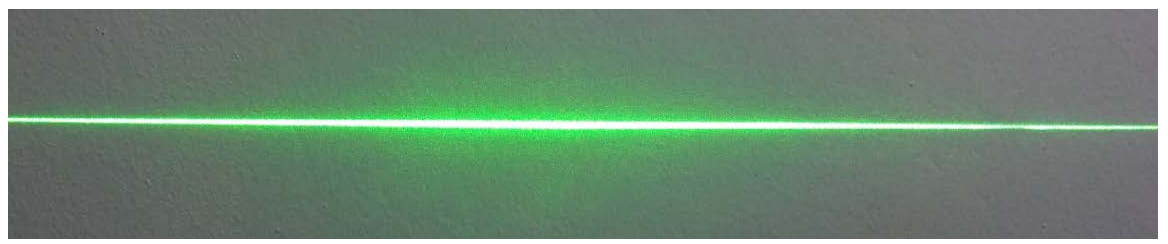

Figure 3. A light sheet produced from $532 \mathrm{~nm} 50 \mathrm{~mW}$ laser module with single rod lens. The field of view is $120 \mathrm{~cm}$ wide. 


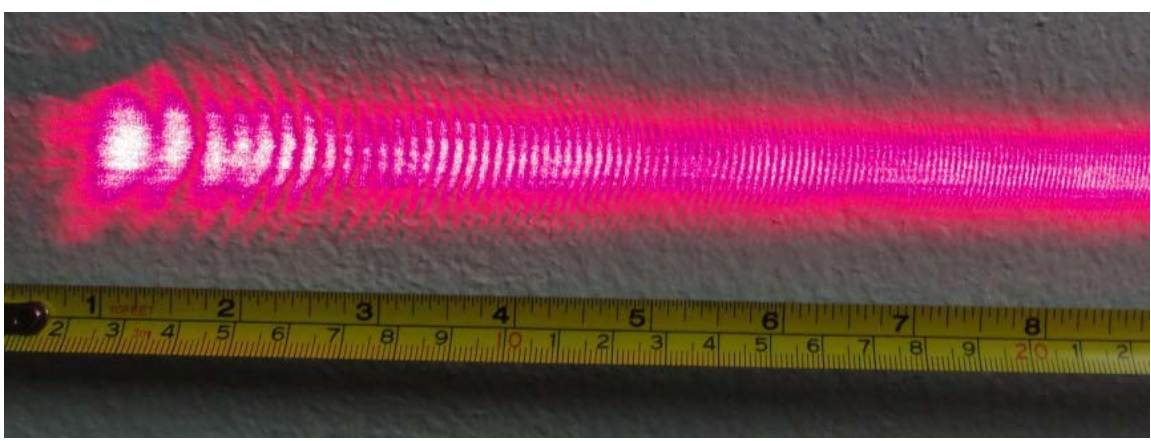

Figure 4. A light sheet produced from $650 \mathrm{~nm} 30 \mathrm{~mW}$ laser module with pseudo-Fresnel lens.

the most consistent in laser sheet thickness at distances from light source to background of 30, 50, and $70 \mathrm{~cm}$ (Table 2).

\section{Discussion}

From the research results, it could be concluded that the laser module of $532 \mathrm{~nm}$ $50 \mathrm{~mW}$ produces adequately thin laser sheet, and its width remains relatively constant in a wide range of distance from light source to background. Here, the laser module of $532 \mathrm{~nm}$ is chosen over the one of $405 \mathrm{~nm}$ because the former is within the wavelength spectrum that human eye and camera lens have high percentage of sensitivity [10] and, consequently, yields high quality images/video file. Even though the produced laser sheet is thin, the distribution of the light intensity of the laser sheet emitted from $532 \mathrm{~nm} 50 \mathrm{~mW}$ laser module is not a true plane. The laser sheet intensity profile observed here is similar to that theoretically analyzed by [7]. However, this laser module still has the following advantages. It is budget-friendly (less than 35 USD) and widely accessible. Most importantly, the experiment setup configuration is simple and requires only one lens component (Figure 5).

The proposed laser module is suitable for quantitative flow visualization experiments where solid particles are distributed in the flow. Since the laser sheet is not a true plane, nonhomogeneous light intensity profile (both cross-wise and length-wise), the following factors and parameters should be taken cautiously when setting up the flow visualization experiment in order to ensure the validity and reproducibility of the experiment. They are flow tank dimensions, Reynolds number, dynamic similitude, and wall factor. The area of the plane of view should not exceed the area of the created laser sheet in order to reduce the amount of scattered light; as a result, the dimensions of the flow tank should be adjusted accordingly. The test flow conditions and the scaled models should meet Reynolds number and, ultimately, dynamic similitude requirements to ensure that the model and the testing conditions have the same dimensionless parameters. Typical particle flow visualization is carried out in a confining container; thus, particle-wall interaction could alter the micro-dynamic of the particle flow near the walls [11] [12] [13]. The wall factor which depends on the ratio 


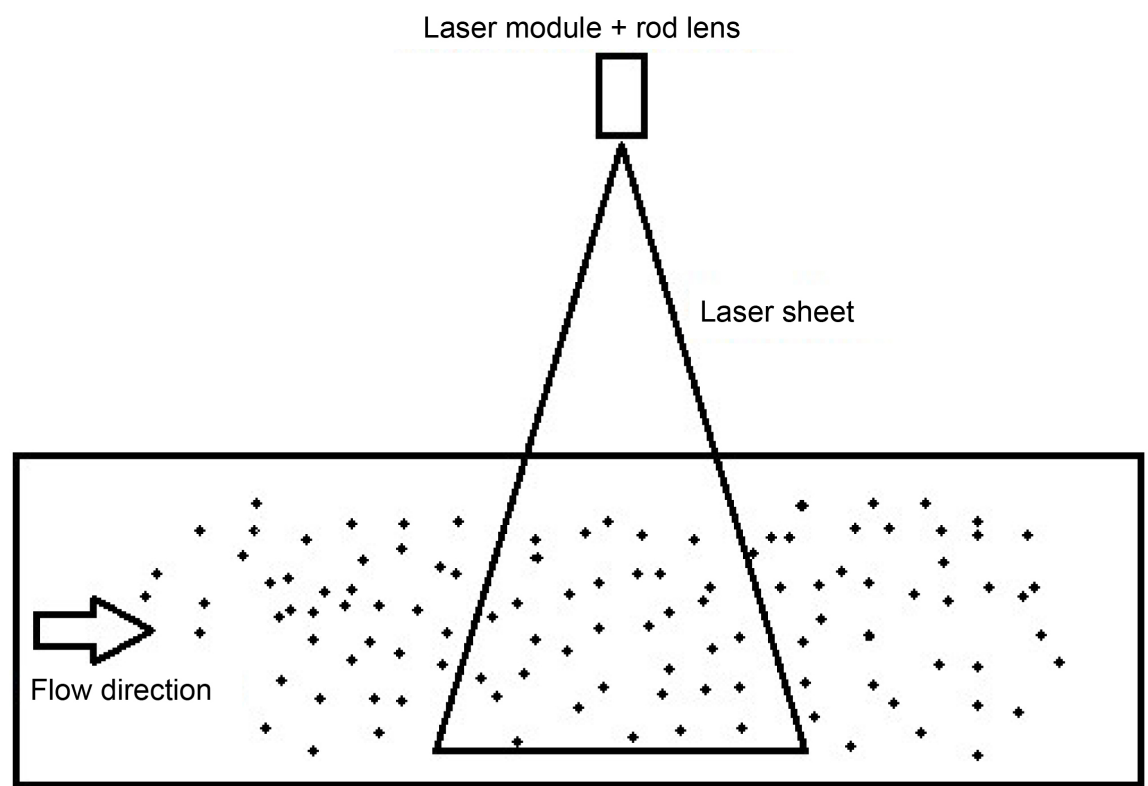

Figure 5. A schematic illustration of the proposed experimental arrangement for particle image velocimetry in a flow tank. A video camera that is capable of recording multiple frames per second is used to record particle movement in the illuminated region. The recorded video file is later split into multiple frames via any image processing software. A vector map representing grain movements is generated from image frames between time intervals via particle image velocimetry software, such as JPIV which is an open source program. The size of interrogation area for velocity vector evaluation should be small so that the velocity gradients are not significant [5].

of particle diameter to effective container diameter [14] should be taking into consideration before building flow tank and selecting particle size.

A practical and simple flow visualization experiment setup for qualitative observation and quantitative analysis of the interaction between fluid media and solid particles is depicted in Figure 5. Prior to building a flow tank and selecting seeded particle size, the following parameters should be determined: Reynolds number, dynamic similitude, and wall factor. The motion of sediments in a flow can be observed by illuminating the light sheet in the interested flow region. The particle motion is recorded by a video camera that is capable of taking multiple frames per second and having a narrow depth of view. The recorded video file can be played in a slow-motion mode so students/researchers can visually observe and qualitatively analyze the particle motion and/or fluid-particle interaction. An open source software package for Particle Imaging Velocimetry (PIV) can calculate the local velocity of particles from still images extracted from the video and create a vector map depicting particle motion. The flow experiment setup proposed here is served as a profound tool for students to understand complicated earth surface processes especially the dynamic interaction between the movement of water and sediment flux. This proposed flow visualization experiment is accessible and inexpensive, and the configuration is simple to setup. Most importantly, this flow visualization technique could serve as a fundamental 
tool for earth surface process education and can further be applied to sedimentary process modeling.

\section{Acknowledgements}

This project is funded by the Faculty of Science, Chiang Mai University, Chiang Mai, Thailand.

\section{References}

[1] Ota, J.J. and Perrusquia, G.S. (2013) Particle Velocity and Sediment Transport at the Limit of Deposition in Sewers. Water Science \& Technology, 67, 959-967. https://doi.org/10.2166/wst.2013.646

[2] Yin, S., Zhang, M., Guo, Z., Liao, H. and Wang, X. (2013) Numerical Investigations on the Effect of Total Pressure and Nozzle Divergent Length on the Flow Character and Particle Impact Velocity in Cold Spraying. Surface and Coatings Technology, 232, 290-297. https://doi.org/10.1016/j.surfcoat.2013.05.017

[3] Agati, L., et al. (2014) Quantitative Analysis of Intraventricular Blood Flow Dynamics by Echocardiographic Particle Image Velocimetry in Patients with Acute Myocardial Infarction at Different Stages of Left Ventricular Dysfunction. European Heart Journal, 15, 1202-1212.

[4] Adrian, R.J. (1991) Particle-Imaging Techniques for Experimental Fluid Mechanics. Annual Review of Fluid Mechanics, 23, 261-304. https://doi.org/10.1146/annurev.fl.23.010191.001401

[5] Raffel, M., Willert, C.E., Wereley, S. and Kompenhans, J. (2013) Particle Image Velocimetry: A Practical Guide. 2nd Edition, Springer, New York.

[6] Adrian, R.J. and Westerweel, J. (2011) Particle Image Velocimetry. Cambridge University Press, Cambridge.

[7] Prenel, J.P. and Jeudy, M. (1998) A New Versatile Laser Sheet Generator for Flow Visualization. Optics \& Laser Technology, 30, 533-538. https://doi.org/10.1016/S0030-3992(99)00006-7

[8] Diemunsch, G. and Prenel, J.P. (1987) A Compact Light Sheet Generator for Flow Visualizations. Optics \& Laser Technology, 19, 141-144. https://doi.org/10.1016/0030-3992(87)90052-1

[9] Pan, C., Min, J., Liu, X. and Gao, Z. (2008) Investigation of Fluid Flow in a Dual Rushton Impeller Stirred Tank Using Particle Image Velocimetry. Chinese Journal of Chemical Engineering, 16, 693-699. https://doi.org/10.1016/S1004-9541(08)60142-1

[10] Schubert, E.F. (2006) Light Emitting Diodes. Cambridge University Press, Cambridge. https://doi.org/10.1017/CBO9780511790546

[11] Zhou, Y.C., Yu, A.B., Stewart, R.L. and Bridgwater, J. (2004) Microdynamic Analysis of the Particle Flow in a Cylindrical Bladed Mixer. Chemical Engineering Science, 59, 1343-1364. https://doi.org/10.1016/j.ces.2003.12.023

[12] Decuzzi, P., Lee, S., Bhushan, B. and Ferrari, M. (2005) A Theoretical Model for the Margination of Particles Within Blood Vessels. Annals of Biomedical Engineering, 33, 179-190. https://doi.org/10.1007/s10439-005-8976-5

[13] Chhabra, R.P., Agarwal, S. and Chaudhary, K. (2003) A Note on Wall Effect on the Terminal Falling Velocity of a Sphere in Quiescent Newtonian Media in Cylindrical Tubes. Powder Technology, 129, 53-58. 
https://doi.org/10.1016/S0032-5910(02)00164-X

[14] Machac, I. and Lecjaks, Z. (1995) Wall Effect for a Sphere Falling through a Non-Newtonian Fluid in a Rectangular Duct. Chemical Engineering Science, 50, 143-148. https://doi.org/10.1016/0009-2509(94)00211-9

\section{Scientific Research Publishing}

Submit or recommend next manuscript to SCIRP and we will provide best service for you:

Accepting pre-submission inquiries through Email, Facebook, LinkedIn, Twitter, etc. A wide selection of journals (inclusive of 9 subjects, more than 200 journals)

Providing 24-hour high-quality service

User-friendly online submission system

Fair and swift peer-review system

Efficient typesetting and proofreading procedure

Display of the result of downloads and visits, as well as the number of cited articles Maximum dissemination of your research work

Submit your manuscript at: http://papersubmission.scirp.org/

Or contact gep@scirp.org 